\title{
Using CRISPR Gene Editing to Prevent Accumulation of Lipids in Hepatocytes
}

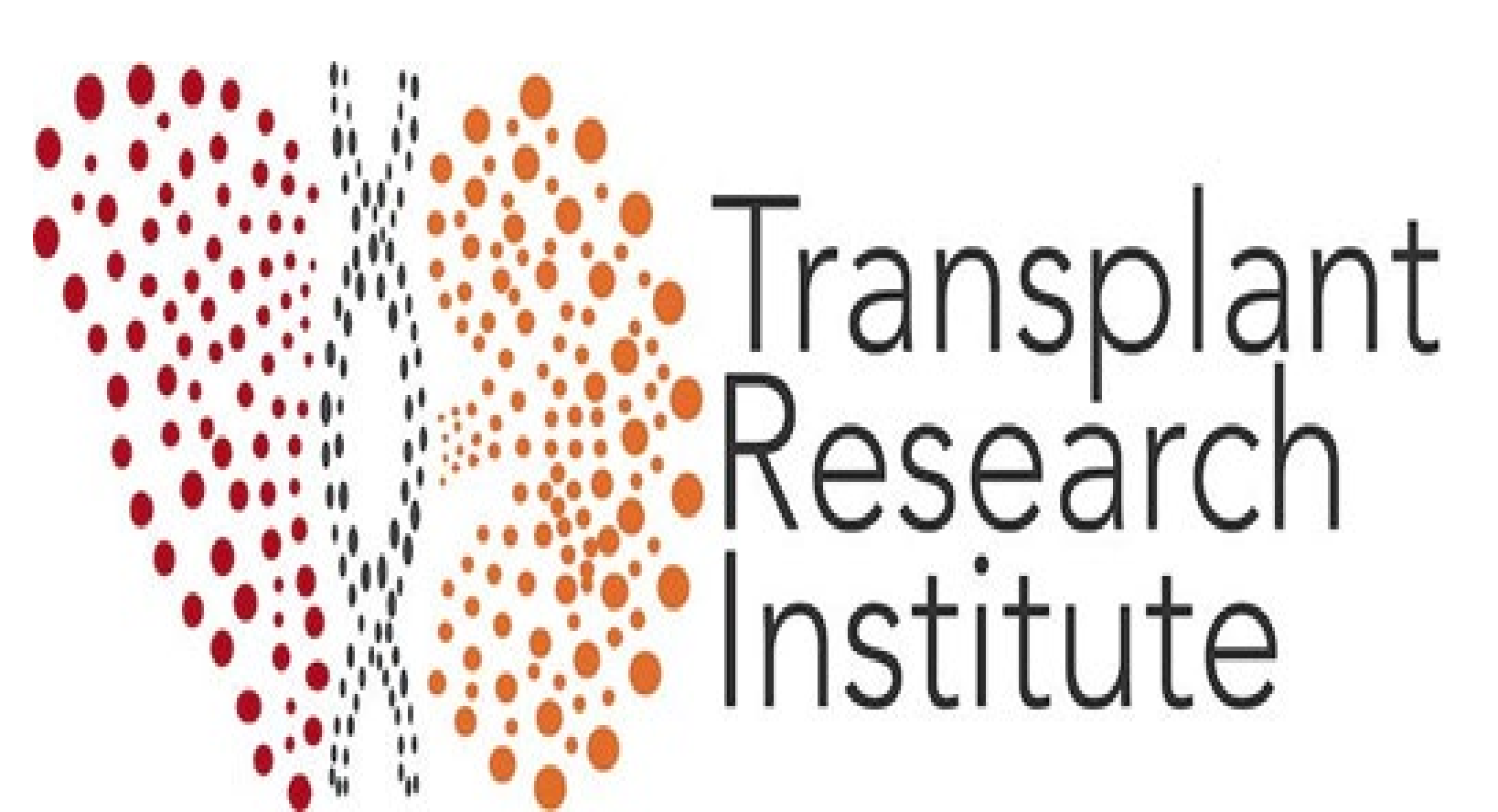

\section{Background}

CRISPR gene editing technology can be used to modify the expression of genes known to play a role in lipid accumulation in hepatocytes.

Specifically, fatty acid transport proteins 2 and 5 (FATP2 \& 5), located in the plasma membrane, are present at increased levels in people with nonalcoholic fatty liver disease ${ }^{1}$. This experiment aimed to reduce expression of FATP 2 \& 5 by using a dead Cas9 with an appended inhibitory domain (KRAB) that acts on the promotor region of the gene. The mRNA expression, fatty acid assays, and flow cytometry were used to evaluate the efficiency of the CRISPR-Cas9 inhibitory system.

\section{Methods}

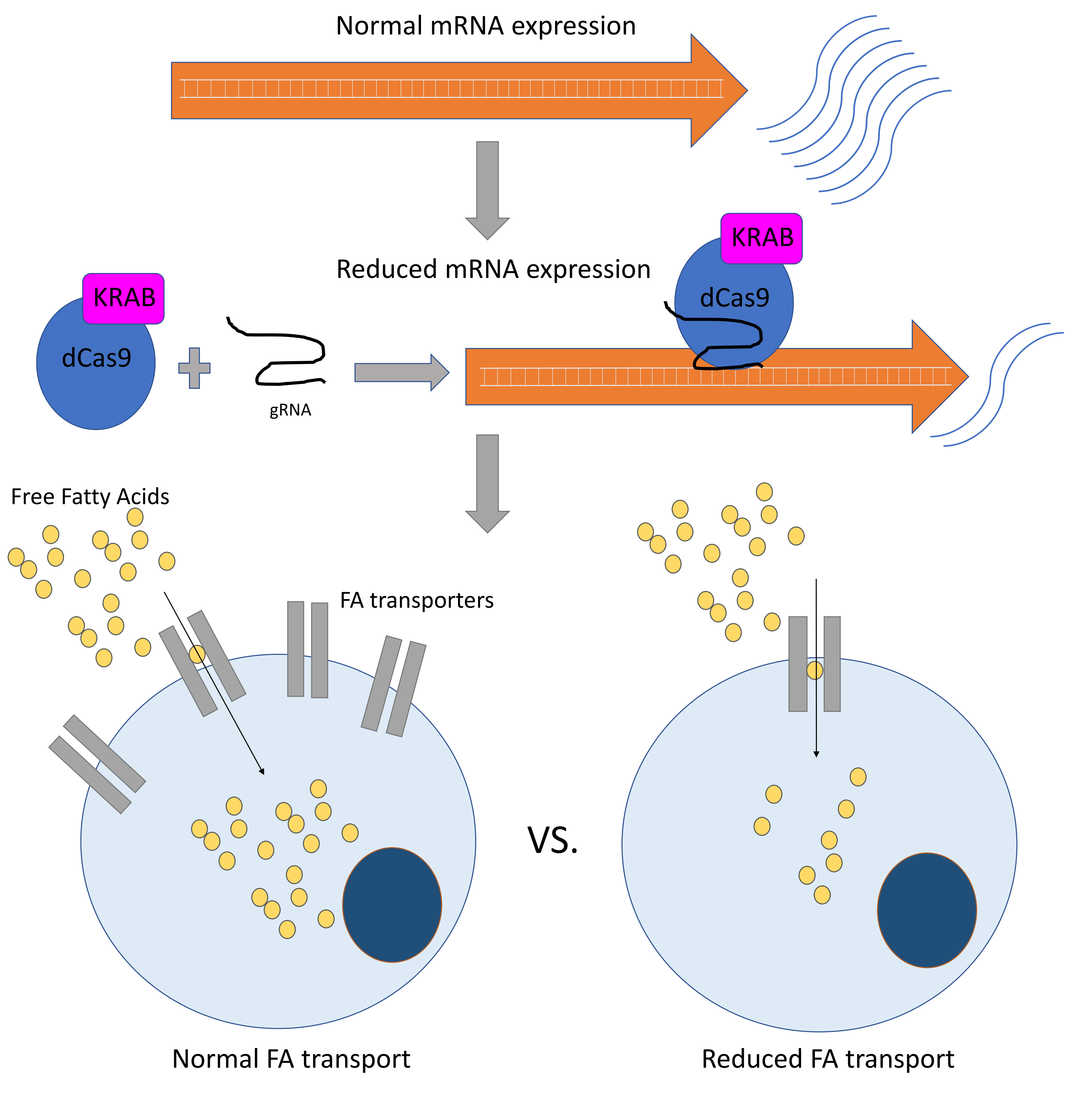

Erin Young, Christine Watkins, Murat Dogan, and Cem Kuscu

Department of Surgery, James D. Eason Transplant Center

University of Tennessee Health Science Center

Memphis, TN USA
METHODIST

UNIVERSTTY HOSPITAL

James D. Eason

Tranșplant Institute

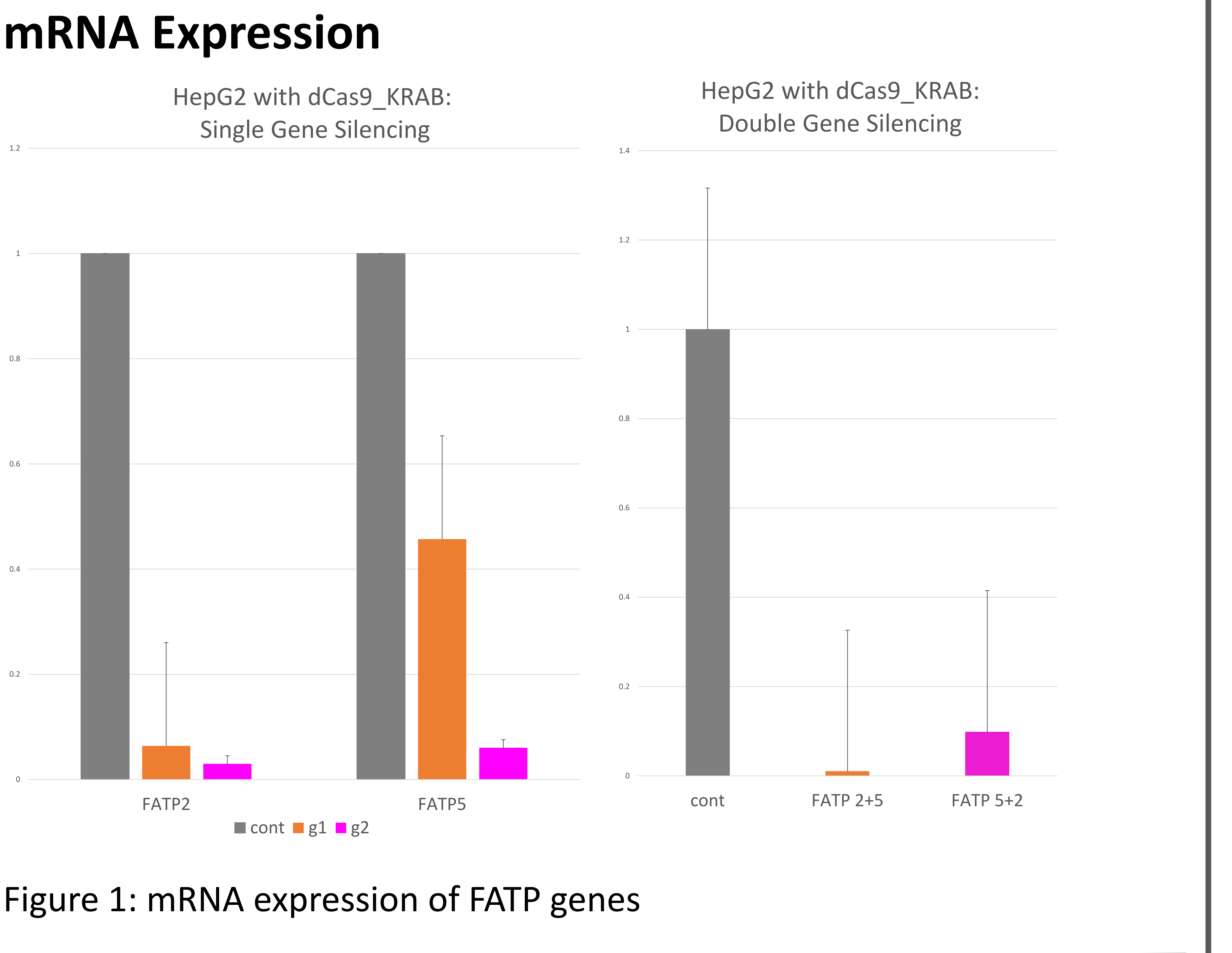

Figure 1: mRNA expression of FATP genes

\section{Fatty Acid Assays}

A mixture of palmitic and oleic acids in a 2:1 ratio (total concentration $200 \mu \mathrm{M}$ ) was added to the cells and allowed to incubate. BODIPY stain was added to highlight lipid inside the cells.
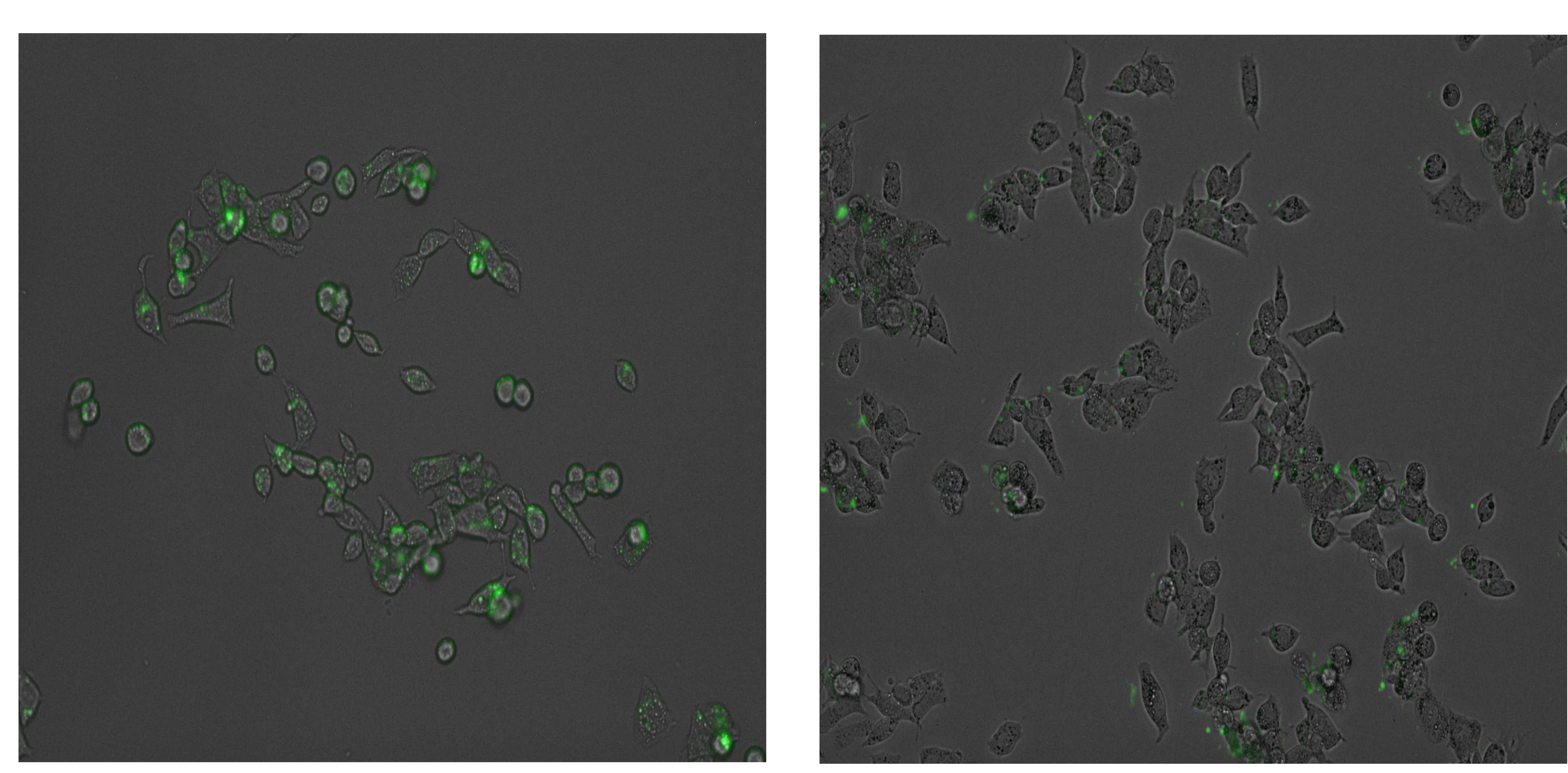

Figure 2: Left: control, Right: inhibition of FATP2 gRNA2

\section{Flow Cytometry}

\begin{tabular}{|c|c|l|l|}
\hline & Sample Name & Subset Name & Count \\
\hline$\square$ & CK2021-10-20LFA Cont.0001.mqd & Single Cells & 16603 \\
\hline$\square$ & CKO021-10-20LFA FATP2g2.0001.mqd & Single Cells & 12293 \\
\hline$\square$ & CK2021-10-20LFA FATP5g2.0001.mqd & Single Cells & 16378 \\
\hline
\end{tabular}

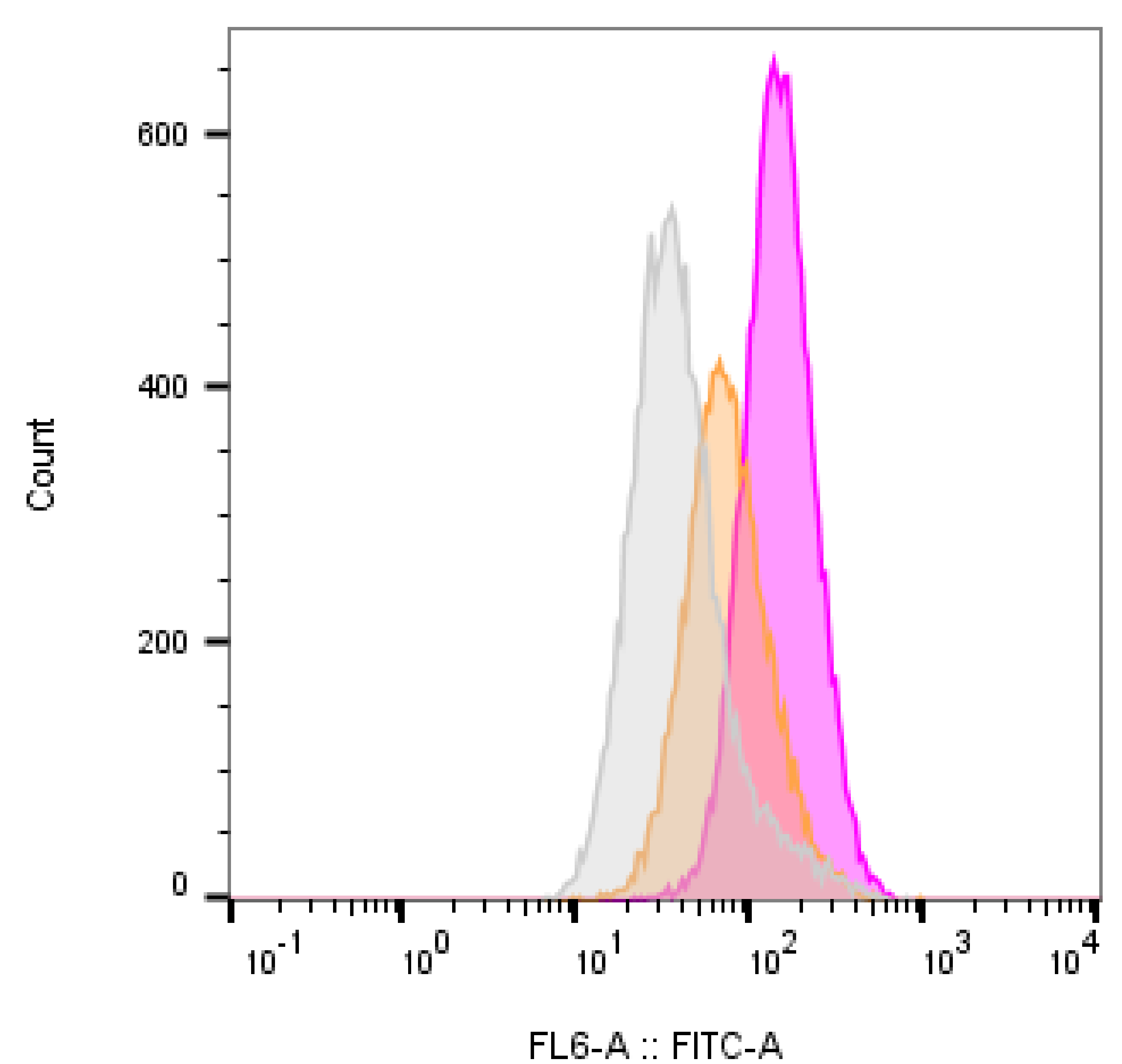

Figure 3: Flow cytometry results from BODIPY stained cells

\section{Discussion}

Although the results from mRNA expression levels and fatty acid assays were expected, the same level of inhibition does not seem to be observed in the flow cytometry. Current work is aimed at deciphering the mechanism behind why lipid accumulation is not inhibited to the same extent, such as possible upregulation of the uninhibited transporter. Consequently, targeting both FATP2 \& 5 in the same cell line may produce the desired results. Additionally, other future projects include running Seahorse metabolic analysis. 